\title{
Prototype to measure bracket debonding force in vivo
}

\author{
Jéssika Lagni Tonus¹, Fernanda Borguetti Manfroi², Gilberto Antonio Borges³, \\ Eduardo Correa Grigolo ${ }^{4}$, Sérgio Helegda 4 , Ana Maria Spohr ${ }^{5}$
}

DOI: http://dx.doi.org/10.1590/2177-6709.22.1.082-088.oar

Introduction: Material biodegradation that occurs in the mouth may interfere in the bonding strength between the bracket and the enamel, causing lower bond strength values in vivo, in comparison with in vitro studies. Objective: To develop a prototype to measure bracket debonding force in vivo and to evaluate, in vitro, the bond strength obtained with the prototype. Methods: A original plier (3M Unitek) was modified by adding one strain gauge directly connected to its claw. An electronic circuit performed the reading of the strain gauge, and the software installed in a computer recorded the values of the bracket debonding force, in kgf. Orthodontic brackets were bonded to the facial surface of 30 bovine incisors with adhesive materials. In Group 1 ( $\mathrm{n}=15)$, debonding was carried out with the prototype, while tensile bond strength testing was performed in Group $2(\mathrm{n}=15)$. A universal testing machine was used for the second group. The adhesive remnant index (ARI) was recorded. Results: According to Student's $t$ test $(\alpha=0.05)$, Group $1(2.96 \mathrm{MPa})$ and Group $2(3.08 \mathrm{MPa})$ were not significantly different. ARI score of 3 was predominant in the two groups. Conclusion: The prototype proved to be reliable for obtaining in vivo bond strength values for orthodontic brackets.

Keywords: Brackets. Bond strength. Enamel.

Introdução: a biodegradação de materiais que ocorre na cavidade bucal pode interferir na resistência de união entre o braquete e o esmalte, causando baixos valores de resistência de união in vivo, em comparação aos valores in vitro. Objetivo: o objetivo do presente estudo foi desenvolver um protótipo para mensurar, in vivo, a força de descolagem de braquetes e avaliar, in vitro, a resistência de união obtida com o uso do protótipo. Métodos: um alicate (3M Unitek) foi modificado por meio da adição de um extensômetro diretamente conectado à garra do alicate. Um circuito eletrônico realizou a leitura do extensômetro, e um software instalado em um computador registrou os valores de força de descolagem do braquete em kgf. Os braquetes ortodônticos foram colados com material adesivo na face vestibular de 30 dentes incisivos bovinos. No Grupo $1(\mathrm{n}=15)$, a descolagem foi realizada com o protótipo, enquanto no Grupo 2 ( $\mathrm{n}=15)$ foi realizado teste de resistência de união à tração, utilizando-se uma máquina universal de ensaios. O índice de adesivo remanescente (ARI) foi analisado. Resultados: de acordo com o teste de $t$ de Student $(\alpha=0,05)$, os grupos 1 (2,96 MPa) e 2 (3,08 MPa) não foram estatisticamente diferentes. O escore 3 do ARI foi predominante nos dois grupos. Conclusão: o protótipo mostrou-se confiável para se obter, in vivo, os valores de resistência de união dos braquetes ortodônticos.

Palavras-chave: Braquetes. Esmalte. Resistência de união.

${ }^{1}$ Undergraduate student, Pontifícia Universidade Católica do Rio Grande do Sul, Department of Dental Materials, Brazil.

${ }^{2} \mathrm{PhD}$ student, Pontifícia Universidade Católica do Rio Grande do Sul, Department of Dental Materials, Brazil.

${ }^{3}$ Adjunct Professor, Universidade de Uberaba, Department of Restorative Dentistry, Brazil.

${ }^{4}$ Engineer, Pontifícia Universidade Católica do Rio Grande do Sul, Instituto Ideia, Brazil.

${ }^{5}$ Associate Professor, Pontifícia Universidade Católica do Rio Grande do Sul, Department of Dental Materials, Brazil.
How to cite this article: Tonus JL, Manfroi FB, Borges GA, Grigolo EC, Helegda S, Spohr AM. Prototype to measure bracket debonding force in vivo. Dental Press J Orthod. 2017 Jan-Feb;22(1):82-8.

DOI: http://dx.doi.org/10.1590/2177-6709.22.1.082-088.oar

Submitted: May 27, 2016 - Revised and accepted: September 12, 2016

» The authors report no commercial, proprietary or financial interest in the products or companies described in this article.

Contact address: Ana Maria Spohr

Avenida Ipiranga 6681, bloco 6 - Faculdade de Odontologia

CEP: 90.619900 - Porto Alegre/RS, Brasil - E-mail: ana.spohr@pucrs.br 


\section{INTRODUCTION}

A stable interface between the bonding material and the bracket, as well as between the bonding material and the enamel, is important to withstand the loads generated by an activated arch. ${ }^{1}$

Using universal testing machines, direct bracket bonding to dental enamel and the forces required to debond the brackets have been studied, in vitro, by means of shear or tensile strength., ${ }^{2,3}$ Regardless of the precision obtained in the measurement of the debonding forces, the universal testing machines are expensive, large and complex to handle. Due to the proportions, it may be impossible to use it for in vivo studies. Furthermore, the complex interaction processes that exist in the oral cavity cannot be completely reproduced by in vitro studies. ${ }^{4}$

The oral cavity is a challenging environment for dental materials, especially regarding the adhesion process. ${ }^{5}$ The contact of adhesive systems and composite resins with the oral medium is associated with an ageing pattern, which may alter the composition and the mechanical properties of the polymers. ${ }^{6}$ Material biodegradation may interfere in the bonding between the bracket and the enamel, ${ }^{7}$ causing lower bond strength values in vivo, in comparison with in vitro values. ${ }^{8}$

Because in vitro bond strength cannot be correlated with clinical failure indexes, ${ }^{9}$ and facing the necessity of creating a method to test the effects of the oral medium on the composite resins used in orthodontics, different devices have been developed to measure the bracket debonding force in vivo. ${ }^{10-12}$ Usually, strain gauges are bonded to the handle ${ }^{10}$ or to the arm of the pliers. ${ }^{11,12}$ The force obtained is a measure of the deformation that occurs in the handle or arm of the pliers during the bracket debonding procedure, and the results can be influenced by the way pliers are holded. ${ }^{12}$ No study has developed a device using strain gauges connected directly to the part of the pliers where the bracket is attached for the debonding procedure.

Thus, the aim of the present study was to develop a prototype to measure the bracket debonding force in vivo, using a strain gauge connected directly to the extremity of the pliers where the bracket debonding occurs. The bond strength obtained with the prototype was also compared in vitro by using the tensile bond strength test in a universal testing machine.

\section{METHODS}

\section{Development of the prototype}

A polypropylene plier (Debracketing Instrument - 444-761, Instrument kit - 3M/Unitek, Monrovia, CA, USA) was modified to develop the prototype (Fig 1A), which consists of three basic parts:

1) Modified plier: the pliers have undergone changes from its original design. To install the strain gauge, the original pliers were cut to receive an intermediate part positioned between the active arm of the pliers and the claw (Fig 1B). One strain gauge $(45 \% \mathrm{Ni} ; 55 \% \mathrm{Cu})$ with $10 \mathrm{~mm}$ of a sheet type grid and with temperature compensation for steel (Kyowa, Chofu, Tokyo, Japan) was directly connected to the claw. Another strain gauge served the sole purpose of performing compensation for ambient temperature changes. These strain gauges were maintained in place with adhesive. All parts used in the execution of this prototype were produced in polyacetal. Figure 1C shows a photograph of the prototype.

2) Measurement and control circuit: corresponds to the electronic circuit that performs the reading of the strain gauge mounted on the intermediate part of the prototype and changes the obtained value into an 8 -bit binary number. The value 0 (zero) represents a strength of $0 \mathrm{kgf}$, and the value 255 ( 8 bits) is the maximum measured force of $6.8 \mathrm{kgf}$. This circuit is powered through a USB communication cable. Prior adjustments are necessary for the required performance of the circuit (Wheatstone bridge, amplifier gain and the $\mathrm{AD}$ converter range).

3) PC: A specific software was developed to record the values (in kgf) of the bracket debonding force. The software was programmed in C (programming language) and was designed to enable appropriate use in a research environment. The software was installed on a notebook with a Windows operating system. The software has a calibration system, and calibration was performed with weights ranging from $0.5 \mathrm{~kg}$ to $6 \mathrm{~kg}$. A known load $(\mathrm{kg})$ was applied to the claw, and the measurements were recorded in kgf. A simple linear regression analysis was applied to adjust the data $\left(\mathrm{R}^{2}=0.99\right)$.

Figure 2 is an image of the prototype and the measurement and control circuit. Figure 3 is a representative diagram of the parts of the prototype. 

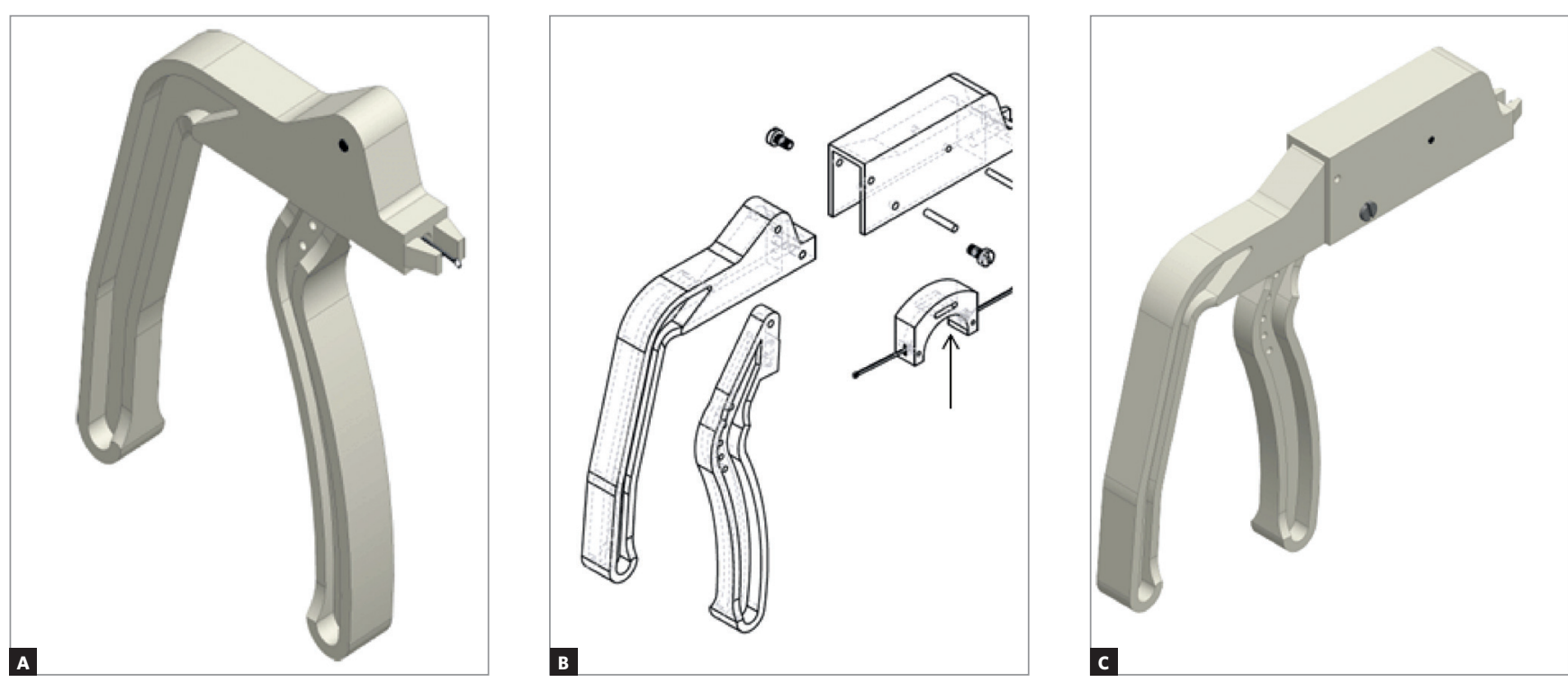

Figure 1 - A) Original plier. B) Exploded image of the intermediate part of the prototype (The arrow indicates the localization of the strain gauges). C) Prototype.

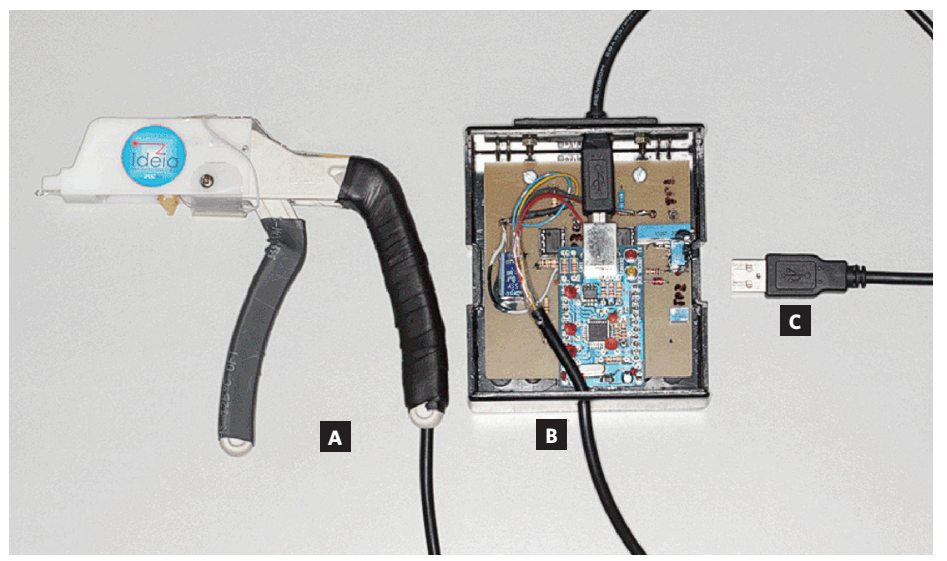

Figure 2 - A) Prototype after electronic instrumentation; B) Measurement and control circuit; C) USB communication cable.

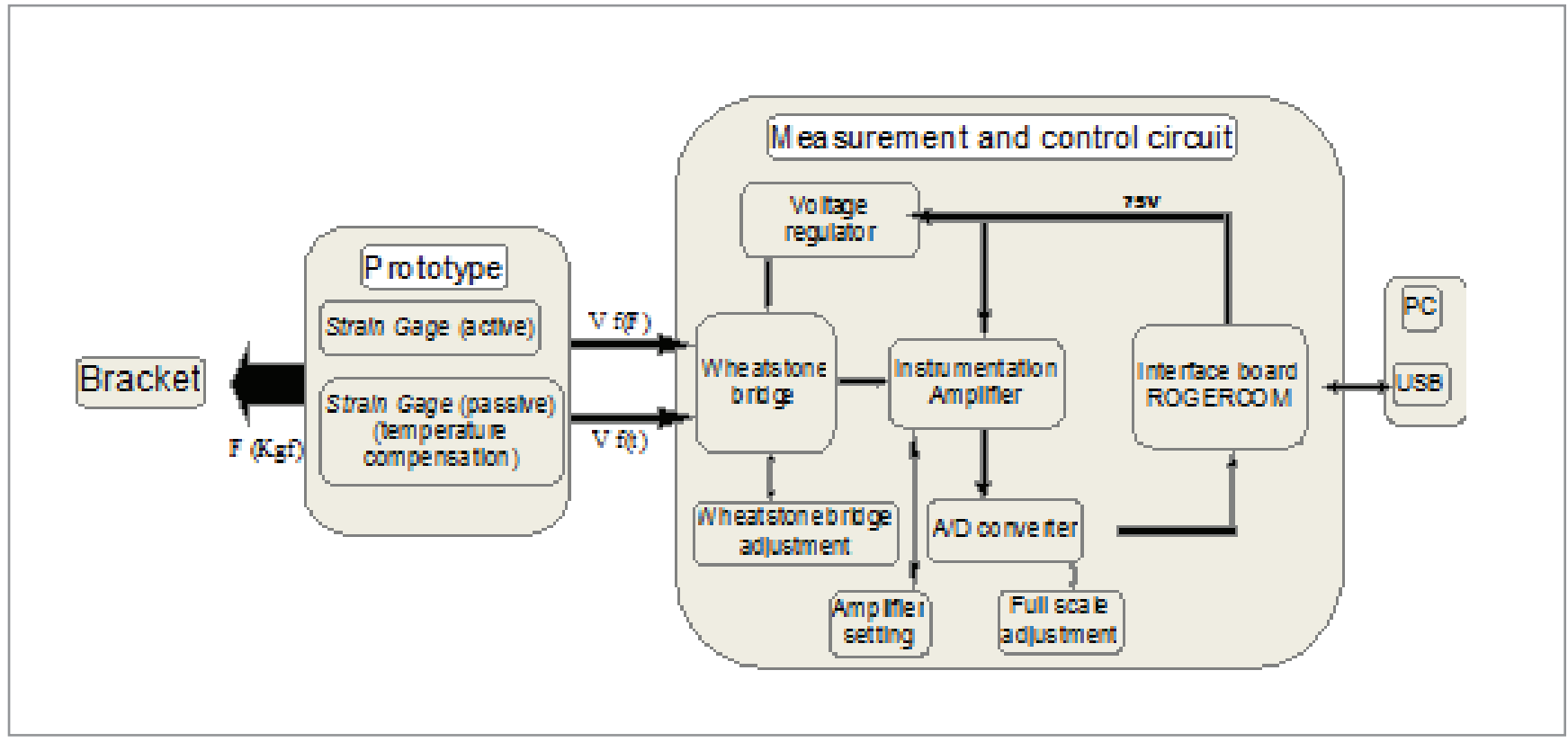

Figure 3 - Representative diagram of the parts of the prototype. 


\section{Prototype gauging procedure}

To measure the accuracy and precision of the prototype, the following weights were used: 1, 2, 3, 4, 5, and $6 \mathrm{~kg}$. Each weight was connected to the claw of the prototype by a stainless steel wire, and the measurement was done by means of displacing the active arm and lifting the weight. The measurements were undertaken by two examiners, who did not standardize the position of the hand on the pliers. Twenty repetitions were performed for each weight. The numerical value recorded by the software installed on the computer was noted, and the arithmetic mean was calculated. The mean temperature in the laboratory during the experiments was $23 \pm 2{ }^{\circ} \mathrm{C}$ and the humidity was $70 \%$.

\section{Bracket debonding trial}

Coronary portions of 30 bovine incisor teeth were embedded in self-cured acrylic. The exposed enamel surface was lightly abraded with \#600 grain silicon carbide abrasive paper in a polisher to obtain a flat enamel surface. The maxillary central incisor brackets (Eurodonto, Curitiba, PR, Brazil) were bonded to the enamel using the following procedure: a) prophylaxis with pumice stone and water; b) etching with phosphoric acid at $37 \%$ for $15 \mathrm{~s}$, followed by washing and drying; c) application of Scotchbond Multi-Purpose adhesive (bond) (3M, St. Paul, MN, USA) on the enamel; d) application of Z100 composite resin (3M, St. Paul, MN, USA) at the base of the bracket and positioning on the tooth with light manual pressure, followed by removal of the excess with a periodontal scaler; e) light curing for $40 \mathrm{~s}$ (10 seconds on each side) with the Optilight Plus appliance (Gnatus, Ribeirão Preto, Brazil). All the bonding was carried out by the same operator. The specimens were stored in $100 \%$ relative humidity at $37^{\circ} \mathrm{C}$ for 24 hours. After storage, specimens were divided into two equal groups:

Group 1 - Bracket debonding with the prototype: Each specimen was placed on a bench lathe. A single operator held the prototype, which was placed on the bracket with the supports aligned in an occlusalgingival direction in contact with the enamel. With the claw hitched onto one of the bracket wings, the prototype was activated by moving the active arm until bracket debonding occurred. The value of the force necessary to remove the bracket was recorded by the software in kgf, transformed into Newtons and divided by the bracket area $\left(14.12 \mathrm{~mm}^{2}\right)$, to obtain resistance values in MPa.

Group 2 - Bracket debonding by tensile testing in a universal testing machine: The specimen was fixed in a metal sleeve on the bottom part of the EMIC-DL 2000 universal testing machine (São José dos Pinhais, Paraná, Brazil). For tensile testing, a claw made of stainless steel wire, $0.40 \mathrm{~mm}$ in diameter and $5 \mathrm{~cm}$ in length, was connected to one of the bracket wings. At the top part of the claw, a $2 \mathrm{~mm}$ thick and $20 \mathrm{~mm}$ long wire segment was welded, which was hitched onto the top part of the universal testing machine. The crosshead speed was $0.5 \mathrm{~mm} / \mathrm{min}$ until bracket debonding occurred. The resistance value was obtained in $\mathrm{MPa}$, as described for Group 1.

All specimens were examined with a stereomicroscope (Olympus Corp., Tokyo, Japan) at 10x magnification to assess the Adhesive Remnant In$\operatorname{dex}(A R I)$ : Score $0=$ no composite resin left on the tooth; Score 1 = less than half of the composite resin left on the tooth; Score 2 = more than half of the composite resin left on the tooth; Score 3 = all composite resin left on the tooth, with a distinct impression of the bracket mesh.

\section{Statistical analysis}

Student's $t$ test $(\alpha=0.05)$ for paired samples was used for comparison between the examiners. Student's $t$ test $(\alpha=0.05)$ was performed to compare the groups.

\section{RESULTS}

Table 1 compares the mean values obtained by the two examiners, with each weight, during the gauging procedure of the prototype. According to Student's $t$ test for paired samples, there were no significant differences $(p<0.05)$ between the examiners at any weight.

According to Student's $t$ test, the mean bond strength obtained in Group 1 (2.96 MPa) and in Group $2(3.08 \mathrm{MPa})$ were statistically similar (Table 2).

Adhesive Remnant Index score 3 was predominant in the two groups (Table 3 ). 
Table 1 - Comparison between the examiners in each weight.

\begin{tabular}{|c|c|c|c|c|}
\hline Comparison & $n$ & Mean (Kgf) & Standard deviation & $p$ value \\
\hline A - $1 \mathrm{~kg}$ & 20 & 1.04 & 0.08 & \multirow{2}{*}{0.30} \\
\hline B - 1 kg & 20 & 1.07 & 0.08 & \\
\hline A - $2 \mathrm{~kg}$ & 20 & 2.03 & 0.07 & \multirow{2}{*}{0.20} \\
\hline B - $2 \mathrm{~kg}$ & 20 & 2.06 & 0.09 & \\
\hline A - $3 \mathrm{~kg}$ & 20 & 2.95 & 0.06 & \multirow{2}{*}{0.08} \\
\hline B - $3 \mathrm{~kg}$ & 20 & 3.01 & 0.09 & \\
\hline A - $4 \mathrm{~kg}$ & 20 & 4.08 & 0.08 & \multirow{2}{*}{0.44} \\
\hline B - $4 \mathrm{~kg}$ & 20 & 4.04 & 0.09 & \\
\hline A - $5 \mathrm{~kg}$ & 20 & 5.01 & 0.09 & \multirow{2}{*}{0.16} \\
\hline B - $5 \mathrm{~kg}$ & 20 & 5.05 & 0.07 & \\
\hline A - 6 kg & 20 & 6.08 & 0.08 & \multirow{2}{*}{0.32} \\
\hline B - $6 \mathrm{~kg}$ & 20 & 6.05 & 0.09 & \\
\hline
\end{tabular}

${ }^{*} p>0.05$ indicates no significant difference between the examiners

$A$ - examiner $A$

B - examiner B

Table 2 - Comparison of mean bond strength (MPa) obtained in each group.

\begin{tabular}{ccccc}
\hline Group & n & Mean & SD & p \\
Group 1 & 15 & 2.96 & 0.32 & \\
Group 2 & 15 & 3.08 & 0.40 & $>0.05$ \\
\hline
\end{tabular}

Group 1: prototype

Group 2: tensile test in a universal testing machine.

\section{DISCUSSION}

The prototype of the present study was an evolution of a device which had two strain gauges bonded to the anterior and posterior $2 / 3$ surfaces of the active arm of the pliers. ${ }^{12}$ Because the strain gauges were placed in the active arm of the pliers, they suffered from the influence of the operator's hand. The present prototype has been developed in order to control this problem by placing the strain gauge near the claw, and not in the active arm of the pliers.

Strain gauges are defined as localized mechanical deformation sensors, since all and any phenomenon responsible for mechanical deformation can be analyzed. Therefore, strain gauges are transducers that convert mechanical displacement into a range of electrical resistance..$^{13}$
Table 3 - Analysis of Adhesive Remnant Index (ARI).

\begin{tabular}{ccccc}
\hline & Score 0 & Score 1 & Score 2 & Score 3 \\
Group 1 & - & $1(7 \%)$ & $1(7 \%)$ & $13(86 \%)$ \\
Group 2 & - & - & $2(13 \%)$ & $13(86 \%)$ \\
\hline
\end{tabular}

Group 1: prototype.

Group 2: tensile test in a universal testing machine.

Strain gauges are very sensitive and temperature alterations are able to influence the measurements. ${ }^{14}$ To compensate for any possible temperature alterations, the following procedures were adopted: a) use of an electrical resistance strain gauge with temperature compensation for steel that self-compensates eventual temperature variations, and; b) control of the laboratory mean temperature during the experiments.

In the present study, the strain gauges were bonded in the intermediate part positioned between the active arm of the plier and the claw. One strain gauge was directly connected to the claw. When the plier was used to debond the brackets, the strain gauge metal grid resistance generated a tension $(\mathrm{mV})$. The small amount of tension generated was multiplied by an amplifier circuit in the electronic circuit, 
which performed the reading of the strain gauge, into binary numbers that were converted into kgf.

Weights from 1 to $6 \mathrm{~kg}$ were used to gauge the prototype. The mode of holding the prototype was not standardized between the two examiners, and there was no statistically significant difference in the values obtained between the examiners at any weight. This means that the prototype was not influenced by the way that it was held - as in another study ${ }^{12}$-, confirming that the new prototype is superior to the previous one.

After gauging the prototype, in vitro orthodontic bracket debonding was performed. Since the bracket debonding performed with a universal testing machine is not dependent on operator variation, the values obtained with this method were compared to the values obtained with the prototype to evaluate its reliability. The tensile test on the universal testing machine (Group 2) tried to reproduce the same conditions as debonding with the prototype. For this purpose, a $0.40 \mathrm{~mm}$ in diameter stainless steel wire claw was made reproducing the same thickness as the prototype claw (Group 1). Along with that, the claw made for the test machine was also connected on a single wing of the bracket at the testing time, reproducing the same position used by the prototype claw at the debonding moment. Although it is named tensile test, it is known that not only tensile forces occur at the debonding moment of the bracket, but that there is also an interaction of tensile, shear and compressive forces. ${ }^{15}$

Debonding of the bracket was performed under a constant crosshead speed of $0.5 \mathrm{~mm} / \mathrm{min}$ in the universal testing machine. This load speed is generally used in spite of not corresponding to clinical conditions due to the fact that in vivo debonding occurs at a higher speed. ${ }^{1}$ Therefore, when the prototype was applied, a speed higher than $0.5 \mathrm{~mm} / \mathrm{min}$ was probably used for bracket removal. Despite the fact that differences existed between the methodologies used for debonding, the bond strength did not differ statistically between the prototype $(2.96 \mathrm{MPa})$ and the tensile test on the universal testing machine $(3.08 \mathrm{MPa})$. This suggests that the prototype might be a useful tool for measuring bond strength in vivo.

Orthodontic bracket bonding to teeth requires that the bond system applied must provide sufficient bond strength to withstand the forces that occur during the orthodontic mechanics and chewing. For clinical situ- ations, some authors suggest that values between 6 and $8 \mathrm{MPa}$ are appropriate. ${ }^{16,17}$ Bond strength values above $10 \mathrm{MPa}$ are potentially dangerous since they may cause enamel fractures during bracket debonding. ${ }^{18}$ However, it is difficult to establish a numerical value because these values depend on several factors, such as the condition of the substrate, ${ }^{19}$ the material involved, ${ }^{20}$ the devices chosen for the test, ${ }^{21}$ cure time, ${ }^{22}$ and the location where force is applied to the bracket. ${ }^{23}$

Due to the difficulty of comparing and extrapolating the results obtained from in vitro studies to the clinical situation, it remains unknown what minimum bond strength values are required for safe clinical performance of orthodontic bonding procedures. Thus, it would be useful to determine the bracket bond strength values in vivo, by using a device to measure the bracket debonding force directly in the oral cavity.

The ARI scores showed that the fracture pattern was predominantly score 3 in both groups. The composite resin remained completely bonded to the enamel after bracket debonding, which is advantageous since score 3 has the least probability of harming the enamel. ${ }^{24,25}$ Therefore, debonding with the prototype was shown to be a safe method for preserving the enamel surface.

\section{CONCLUSIONS}

The prototype developed proved to be reliable for measuring bracket debonding force in vivo.

\section{Acknowledgments}

The authors thank the Idea Institute of PUCRS for the development of the prototype.

\section{Authors contribution}

Conception or design of the study: JLT, ECG, SH, AMS. Data acquisition, analysis or interpretation: JLT, FBM, GAB, AMS. Writing the article: JLT, ECG, SH, AMS. Critical revision of the article: JLT, FBM, GAB, ECG, SH, AMS. Overall responsibility: AMS. 


\section{REFERENCES}

1. Eliades T, Brantley WA. The inappropriateness of conventional orthodontic bond strength assessment protocols. Eur J Orthod. 2000 Feb;22(1):13-23.

2. Rocha JM, Gravina MA, Campos MJS, Quintão CC, Elias CN, Vitral RW. Shear bond resistance and enamel surface comparison after the bonding and debonding of ceramic and metallic brackets. Dental Press J Orthod. 2014 Jan;19(1):77-85.

3. Espinar-Escalona E, Barrera-Mora JM, Llamas-Carreras JM, Solano-Reina E, Rodríguez D, Gil FJ. Improvement in adhesion of the brackets to the tooth by sandblasting treatment. J Mater Sci Mater Med. 2012 Feb;23(2):605-11.

4. Oilo G. Biodegradation of dental composites/glass-ionomer cements. Adv Dent Res. 1992 Sept;6:50-4

5. Breschi L, Mazzoni A, Ruggeri A, Cadenaro M, Di Lenarda R, De Stefano DO Dental adhesion review: aging and stability of the bonded interface. Dent Mater. 2008 Jan;24(1):90-101

6. Eliades T, Bourauel C. Intraoral aging of orthodontic materials: the picture we miss and its clinical relevance. Am J Orthod Dentofacial Orthop. 2005 Apr:127(4):403-12

7. Matasa C. Microbial attack of orthodontic adhesives. Am J Orthod Dentofacial Orthop. 1995 Aug:108(2):132-41

8. Pickett KL, Sadowsky PL, Jacobson A, Lacefield W. Orthodontic in vivo bond strength: comparison with in vitro results. Angle Orthod. 2001 Apr:71(2):141-8.

9. Sunna S, Rock WP. Clinical performance of orthodontic brackets and adhesive systems: a randomized clinical trial. Br J Orthod. 1998 Nov;25(4):283-7.

10. Brosh T, Kaufman A, Balabanovsky A, Vardimon AD. In vivo debonding strength and enamel damage in two orthodontic debonding methods. J Biomech. 2005 May:38(5):1107-13.

11. Hildebrand NKS, Raboud DW, Heo G, Nelson AE, Major PW. Argon laser vs conventional visible light-cured orthodontic bracket bonding: an in-vivo and in-vitro study. Am J Orthod Dentofacial Orthop. 2007 Apr;131(4):530-6.

12. Prietsch JR, Spohr AM, Silva INL, Beck JCP, Oshima HMS. Development of a device to measure bracket debonding force in vivo. Eur J Orthod. 2007 Dec:29(6):564-70

13. Helfrick AD, Cooper WD. Modern electronic instrumentation and techniques of measurement. 1st ed. Rio de Janeiro: Prentice Hall; 1994. 123 p.
14. Window AL, Holister GS. Strain gauge technology. Elsevier Science Publishing Company, London, 1982, 356 p.

15. Thomas RL, Rijk WG, Evans CA. Tensile and shear stresses in the orthodontic attachment adhesive layer with 3D finite element analysis. Am J Orthod Dentofacial Orthop. 1999 Nov;116(5):530-2.

16. Reynolds IR. A review of direct orthodontic bonding. Br J Orthod. 1975:2(3):1718.

17. Bishara SE, VonWald L, Laffoon JF, Waren JJ. Effect of a self-etch primer/ adhesive on the shear bond strength of orthodontic brackets. Am J Orthod Dentofacial Orthop. 2001 June;119(6):621-4

18. Nkenke E, Hirschfelder U, Martus P, Eberhard H. Evaluation of the bond strength of different bracket-bonding systems to bovine enamel. Eur J Orthod. 1997 June;19(3):259-70

19. Vianna JS, Marquezan M, Lau TC, Sant'Anna EF. Bonding brackets on white spot lesions pretreated by means of two methods. Dental Press J Orthod. 2016 Mar;21(2):39-44

20. Neves MG, Brandão GA, Almeida HA, Brandão AM, Azevedo DR. In vitro analysis of shear bond strength and adhesive remnant index comparing light curing and self-curing composites. Dental Press J Orthod. 2013 May-June;18(3):124-9.

21. Sinhoreti MAC, Consani S, Goes MF, Correr Sobrinho L, Knowles JC. Influence of loading types on the shear strength of the dentin-resin interface bonding. J Mater Sci Mater Med. 2001 Jan;12(1):39-44.

22. Carvalho PE, Santos VM, Isber H, Cotrim-Ferreira FA. Halogen light versus LED for bracket bonding: shear bond strength. Dental Press J Orthod. 2013 Feb;18(1):31. e1-6.

23. Klocke A, Kahl-Nieke B. Influence of force location in orthodontic shear bond strength testing. Dent Mater. 2005 May:21(5):391-6.

24. Olsen ME, Bishara SE, Damon P, Jakobsen JR. Evaluation of Scotchbond multipurpose and maleic acid as alternative methods of bonding orthodontic brackets. Am J Orthod Dentofacial Orthop. 1997 May:111(5):498-501

25. Oliver RG. The effect of different methods of bracket removal on the amount of residual adhesive. Am J Orthod Dentofacial Orthop. 1988 Mar;93(3):196-200. 